\title{
Erratum to: Can augmented feedback facilitate learning a reactive balance task among older adults?
}

\author{
Avril Mansfield ${ }^{1,2,3,4}$ - Anthony Aqui ${ }^{1} \cdot$ Julia E. Fraser $^{1,5}$. \\ Roshanth Rajachandrakumar $^{1,2} \cdot$ Bimal Lakhani $^{6} \cdot$ Kara K. Patterson $^{1,2,3}$
}

Published online: 27 February 2017

(C) Springer-Verlag Berlin Heidelberg 2017

\section{Erratum to: Exp Brain Res (2017) 235:293-304 DOI 10.1007/s00221-016-4790-6}

There was an error in Eq. (4) as it was originally published. Equation (4) should read as follows:

$\mathrm{COG}_{y}=\mathrm{COP}_{y}-\frac{I}{m g h}\left(a_{y 1}-a_{y 2}\right)$

where $\mathrm{COG}_{y}$ is the antero-posterior location of the COG, $\mathrm{COP}_{y}$ is the antero-posterior location of the COP, $g$ is acceleration due to gravity, $a_{y 1}$ is $F_{y 1} / m_{1}$, and $a_{y 2}$ is $F_{y 2} / m_{2} . F_{y 1}$ is the antero-posterior shear force recorded from the force plate upon which the participant stood, $m_{1}$ is the mass of the participant plus the mass of the force plate upon which the participant stood, $F_{y 2}$ is the antero-posterior shear force recorded by an empty force plate on the motion platform, and $m_{2}$ is the mass of the empty force plate on the motion platform. Thus, the term $\left(a_{y 1}-a_{y 2}\right)$ is acceleration of the participants' COG relative to the moving platform.

The online version of the original article can be found under doi: 10.1007/s00221-016-4790-6.

Avril Mansfield

avril.mansfield@uhn.ca

1 Toronto Rehabilitation Institute, University Health Network, Room 11-117, 550 University Ave, Toronto, ON M5G 2A2, Canada

2 University of Toronto, Toronto, ON, Canada

3 Heart and Stroke Foundation Canadian Partnership for Stroke Recovery, Ottawa, ON, Canada

4 Sunnybrook Research Institute, Toronto, ON, Canada

5 University of Waterloo, Waterloo, ON, Canada

6 University of British Columbia, Vancouver, BC, Canada 